\title{
ON THE EFFICIENCIES OF THE STEAM BOILER AND ON THE CONDITIONS OF MAXIMUM ECONOMY.
}

\author{
By Robert H. Thurston. \\ [Presented to the American Society of Mechanical Engineers, Philadelphia Meet- \\ ing, A pril, 1882.]
}

In the design and construction of a steam boiler, and in its operation, problems arise which must be solved, by the mechanical engineer, in their natural order before he can say with confidence that the best interests of the purchaser or proprietor of the apparatus are fully met in its construction and management. Such problems form the subject of this paper.

(1.) The "Efficiency of the Steam Boiler" is the ratio of the total quantity of heat utilized in the production of steam to that set free in the combustion of the fuel. It has as the maximum limit unity. It is a function of area of heating surface and quantity of fuel burned, and of factors dependent upon the character of the fuel and of its combustion, and upon the design of the boiler.

(2.) The "Commercial Efficiency" or the "Efficiency of Capital" employed in the maintenance of steam-generating apparatus of a given power is measured by the ratio of quantity of steam produced to the cost of its continuous production, i. e., by the reciprocal of the total cost of steam per pound or per cubic foot at the required pressure. This efficiency is a maximum when that cost is a minimum.

(3.) The Efficiency of a Given Boiler Plant," as the writer would call it, or the commercial efficiency of a steam boiler already in place and in operation, is still another quantity. It is a maximum when the work done by the boiler can be increased beyond that for which it was proportioned-if designed originally to give maximum efficiency of capital at a pre-arranged power, as above-until the amount of steam made by that boiler per dollar of working expense is made a maximum.

These three efficiencies differ essentially in their character, and are determined by different processes. In the first case, the engineer designing a boiler finds himself called upon to determine what is the maximum efficiency that it will be economical, or otherwise advisable, 
to endeavor to secure, and then calculates the proportions necessary to secure that efficiency. Or, knowing the proportions of any boiler already designed and built, he may be required to calculate its probable efficiency and the quantity of fuel called for to make a certain quantity of steam, i. e., to determine the steam generated per pound of ("oal burned.

In the second case, the designing engineer calculates the proportions of heating surface to grate surface or to fuel burned, where the quantity of steam required is known, and the conditions determining costs, which shall give that quantity of steam at least total running expense.

In the third case, the boiler is in place and in operation, and it is found that it is advisalole to ascertain what quantity of steam can be made when its cost per unit of weight or of volume is a minimum.

In the first two cases, the variable element is usually the area of heating surface per pound of fuel burned in the unit of time; in the last, the rariable is the quantity of fucl burned or of steam made.

(4.) To What Capacity may any Given Boiler be Forced without Exceeding that Cost of Steam at which a Paying Profit is Given? is another problem in team boiler efficiency and one which is of more frequent occurrence, and is usually more important than the preceding.

The economical maximum of steam production is evidently determined by the money value, to the producer, of the stean made.

\section{(1.) Efficiency of the Steam Boiler.}

This case has been studied by Rankine, who deduces a very simple and handy formula for the efficiency of a boiler of known proportions, using a fuel of kuown calorific value.

Taking the rate of conduction of heating surfaces as varying as the square of the difference of temperatures of the gas and of the water on opposite sides of the sheet, the formula

$$
E=\frac{1}{1+\frac{a c^{\prime 2} W^{2}}{S H}}
$$

is readily deduced, in which $E$ is the efficiency, $a$ a constant, $c^{\prime}$ the specitic heat of the furmace gases, and $W$ their weight; while $H$ is the total heat expended and $S$ ' the heating surface. This expression is further transformed into

$$
E_{1}=\frac{B E}{1+\frac{A F}{S}}
$$


in which $E$ is the theoretical evaporative power of the fuel per pound, $E_{1}$ the probable actual evaporation in a boiler in which $F$ is the weight of fuel burned on the unit of area of grate, and $S$ is the area of heating surface per unit of the same area.

$A$ and $B$ are here coefficients, having values respectively of 0.3 to 0.5 and 0.9 to 1 for bituminous coals, according to Rankine, and from 0.3 to 0.5 and from 0.8 to 0.9 with anthracite coal, as determined by experiments made by the writer. The lower values of $A$ are obtained when using a minimum air-supply and the value of that coefficient is seen, by comparing the two equations just given, to vary as the square of the quantity of air supplied to the fuel. The value of $B$ is dependent upon the character of the boiler, being greater as the design and construction are improved.

The following are illustrations of the results thus obtained:

FfFictency of Steam Bonlers.

$\begin{array}{ccccc} & \text { I. } & \text { II. } & \text { III. } & \text { IV. } \\ F & A=0.5 \quad B=1 & A=0.3 \quad B=1 & A=0.5 \quad B=1 & A=0.3 \quad B=1 \\ S & 0.92 & 0.95 & 0.83 & 0.86 \\ 0.17 & 0.92 & 0.91 & 0.78 & 0.82 \\ 0.33 & 0.87 & 0.89 & 0.75 & 0.80 \\ 0.40 & 0.83 & 0.87 & 0.72 & 0.78 \\ 0.50 & 0.80 & 0.83 & 0.68 & 0.75 \\ 0.67 & 0.75 & & & \end{array}$

\section{Expenses of Operation.}

The expenses of operating a steam boiler may be classed under three heads :

(1.) Those costs of boiler and its maintenance which are dependent upon the size and the character of the boiler itself and its attachments, such as interest on cost of boiler and setting, rent of building and other items on construction account, such as taxes, insurance, repairs and depreciation, etc., etc.

(2.) Those costs of operation which are dependent upon the quantity of steam made and of fuel consumed, such as market price of fuel, cost of transportation, storage (an important item on shipboard cspecially), and of feeding into the furnace, cost of feed-water and its introduction into the boiler, and a certain part of other costs of attendance and supply. 
(3.) In addition to these variable expenses are often, perhaps usually, to be counted certain constant expenses which are unaffected by any change of proportions of boiler likely to be made in the assumed case, such as nearly, or quite frequently all, the costs of attendance.

\section{(2.) Commercial Efficiency of the Boiler.}

A given amount of steam being demanded, it may be obtained from a small boiler using fuel extravagantly or from a large boiler using fuel economically. In each case arising in practice, there will be found a certain easily determined proportion of heating surface to grate surface and a definite size of boiler which will, on the whole, supply the desired quantity of steam most economically. Thus:

Let the total cost of fuel per annum and per pound burned per hour on the square foot of grate or on the square metre be called $C$. Let the total cost per annum of boiler, per square foot or per square metre of heating surface, be called $D$, and let $\frac{C}{D}=R$. In the first item is included all items of Class 1, and in the second all of Class 2.

Then the cost of boiler maintenance per annum is $D S G$, where $S$ is the area of heating surface per unit of area of grate and $G$ is the area of grate. The cost of fuel, etc., per annum, as per Class 2, is $C F G$, if $F$ is the weight of fuel burned per unit of area of grate.

The total of costs variable with change of proportion of boiler is

$$
P=D G S+C F G \text {. }
$$

The profitable work of the boiler is measured by the quantity, by weight, of steam made, $F G E_{1}=W ; E_{1}$ being the evaporation of water per unit of weight of fuel.

The ratio of cost to work done is

$$
y=\frac{P}{W}=\frac{D G S+C F G}{F G E_{1}}=\frac{C F+D S}{E_{1} F} .
$$

This quantity being made a minimum by variation of the area $S$, the most economical boiler is obtained.

But $E_{1}$ is a function of $S$ and, taking the value of $E_{1}$ from the equation

$$
E_{1}=\frac{B E}{1+\frac{A \bar{F}}{S}},
$$


we obtain

$$
\begin{array}{r}
y=\frac{(D G S+C F G)\left(1+\frac{A F}{S}\right)}{B E F G}=\frac{D G S+A D F G+C F G+\frac{A C F^{2} G}{S}}{B E F G} \\
=\frac{D S+A D F+C F+\frac{A C F^{2}}{S}}{B E F}
\end{array}
$$

which is a minimum when

$$
S=F \sqrt{\frac{\bar{A} \bar{C}}{D}}=F \sqrt{A R} ; \quad \frac{S}{F}=\sqrt{A \bar{R}} .
$$

In illustration : Let a boiler, set in place, complete with all its appurtenances and in running order, cost $\$ 3$ per square foot of heating surface, and the annual charges on all accounts entered in Class 1, above, be 20 per cent. on this cost, the annual charge becomes $D S=$ $\$ 0.60 \times S$ per square foot of grate, $i . e ., D=\$ 0.60$. Let the cost of operation, as for Class 2 , amount to $\$ 15$ per annum per pound of fuel burned per hour on the square foot of grate; then $C F=\$ 15$; $C=\$ 15 ; \frac{C}{D}=R=25$.

Assume $F=10$ pounds of fuel per hour per square foot of grate, $A=0.5$.

For this case, then, the boiler should have per square foot of grate

$$
S=F \sqrt{A R}=10 \times(0.5 \times 25)^{2 / 2}=35 ;
$$

35 square feet of heating surface.

Similarly we get the following values:

Commercial Efficiency of Botlers.

Ratio of Areas of Heating and Grate Surfaces.

Values of $S$.

\begin{tabular}{rrrrrrrrr}
\hline$F$ & 6 & 10 & 12 & 15 & 20 & 30 & 40 & 50 \\
\hline$R$ & & & & & & & & \\
25 & 21 & 35 & 42 & 52 & 70 & 105 & 140 & 175 \\
16 & 17 & 28 & 34 & 42 & 56 & 84 & 112 & 140 \\
9 & 12 & 21 & 24 & 32 & 42 & 63 & 84 & 105 \\
4 & 8 & 14 & 16 & 21 & 28 & 42 & 56 & 70 \\
\hline
\end{tabular}

These values are 20 or 25 per cent. lower for forced draught. Whole No. Vol. CXIV.-(Third SERTes, Vol. lxxxiv.) 
Where the boiler is worked almost continuously, as in flour mills and some other establishments kept in operation night and day throughout the year, the higher values will be found correct; when the boiler is worked discontinuously or, as in steam fire engines and some classes of steam vessels, a comparatively small proportion of the annual working time of the establishment or whole plant, the values of $S$ become very small.

It is seen that the best area of heating surface will vary nearly as the square root of the total working time per annum. Boilers worked continuously, worked twelve hours out of the twenty-four, or eight honrs in the day, will require, respectively, values of $S$ having the proportion $1,0.7$ and 0.6 nearly.

The total required area of grate is $\frac{W}{E_{1} F}=G$; the total area of heating surface is $\frac{W S}{F E_{1}}=S G=\frac{W(S+A F)}{B E F}$.

The following are examples, in greater detail, of the application of the above:

\section{Expense on Boiler Account and Maximum Commercial EFFICIENCY.}

Cases.

Class $1(D)$.
Stationary.

I. II. III. IV.

Cornish. Tubular. Tubular. Tubular.

Total annual cost of boiler per unit

$$
\text { of } S \text {, }
$$

Interest,

Repairs and depreciation,

Rent, insurance and miscellaneous,

Total value of $D$,

Class $2(C)$.

Fuel (@ $\$ 5$ for I, II, IV; $\$ 4$ for

III) per unit of $F$

Transportation and storage, .

Attendance (variable cost),

Total,

$\begin{array}{rrrr}\$ 1.50 & \$ 2.00 & \$ 3.00 & \$ 2.00 \\ .09 & .12 & .15 & .12 \\ .15 & .20 & .45 & .30 \\ .10 & .07 & 1.00 & .20 \\ .34 & .38 & 1.60 & .62\end{array}$

$\$ 1.50 \quad \$ 2.00 \quad \$ 3.00 \quad \$ 2.00$

$\begin{array}{llll}.09 & .12 & .15 & .12\end{array}$

.30

$\begin{array}{llll}.34 & .38 & 1.60 & .62\end{array}$ 


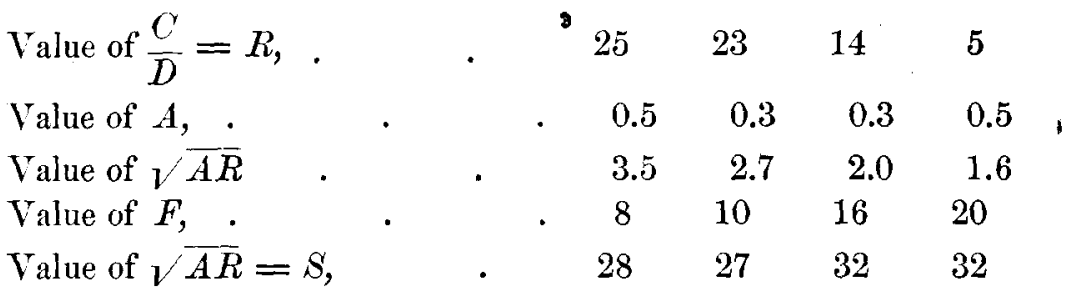

$R$ varies in magnitude very greatly in practice, falling as low as 4 and rising as high as 50 with varying cost of fuel and length of working time.

The engineer thus solves the most important problem in boiler-design which may be thus enunciated: To determine the commercial efficiency of a steam boiler doing a fixed amount of work; or, given all variable expenses of boiler installation, maintenance and operation, to determine what proportion of heating surface to grate surface or fuel burned will give the required amount of power at least total cost.

\section{(3.) Commercial Efficiency of a Given Boiler.}

A second commercial problem may sometimes be presented to the engineer: A steam boiler is in place and in operation; all constant expenses are known and all variable costs of maintenance and operation are determinable. The question arises, or may arise whenever additional steam is called for: How much can be obtained from the apparatus when driven to such an extent as to yield most steam per dollar of total cost of operation? The independent variable is now the quantity of fuel burned in the boiler, and this is, in the established equation, represented by $F$, the fuel burned per unit of area of grate. This problem is thus stated:

Given: All expenses, constant and variable, and the method of variation of the latter and the proportions of the boiler as actually. constructed, to determine that rate of combustion which will make the Commercial Efficiency of the Given Plant a maximum.

For this case, let $K$ represent that total annual expense of working which is independent of Classes (1) and (2) and which falls into Class.

(3) and let $k=\frac{K}{G}$.

Let all other symbols stand as before.

Then the total cost of maintenance and operation will be

$$
P^{\prime}=k G+D G S+C F G
$$


while the work done will be, as duefore,

$$
W=F G E_{1}
$$

The quantity to be made a minimum is, for the present case, the quotient of $P^{\prime}$ by $W$,

$$
y=\frac{P^{\prime}}{W}=\frac{k+D S+C F}{E_{1} F}
$$

$F$ being taken as the independent variable.

This becomes a minimum when we substitute for $E_{1}$ its value $E_{1}=$ , $B E$

$1+\frac{A F}{S}$ and make the first derivative equal zero.

Then we find

$$
F_{1}=\sqrt{\frac{k S+D \bar{S}^{2}}{A C}}
$$

When, in this expression for the value of $F$, giving maximum weight of steam for the dollar expended, we make $k=0$, the expression may be reduced, as obviously should be possible, to the form shown already to be that giving the solution of the first problem :

$$
S=F \sqrt{A R} \text {. }
$$

The following cases illustrate this problem:

Expenses of Boller axd Maximum Economy of Plant.

Cases.

Cost of maintenance: $D$,

Cost of operation:

Cost of operation : $K$
Stationary.

I. II.

Marine.

III. IV.

For maximum fuel and work : $F_{1}, \quad \begin{array}{lllll}16 & 13 & 17 & 21\end{array}$

For maximum efficiency, as before : $F, \begin{array}{lllll}8 & 10 & 16 & 20\end{array}$

Case No. 1 is that of a Cornish boiler, No. 2 that of a multitubular stationary boiler, No. 3 that of a sea-going steamer and No. 4 that of a yacht.

It is seen that in all cases the weight of steam delivered from the boiler and the quantity of fuel burned at maximum commercial efficiency, for the case assumed, are less than where the boiler-once set and still capable of being forced to deliver more steam than originally 
proposed and calculated upon-is worked up to a maximum delivery per dollar of total expense.

"Maximum Commercial Efficiency of Boiler" and "Maximum Efficiency of a Given Plant" are therefore by no means identical conditions, and it will usually be found that when this maximum work can be put on the boiler, it might be done still more economically by a boiler specially designed, as in the first problem, to do the increased quantity of work; the conclusions from this fact being simply that economy dictates that as much steam power as possible should be grouped into a single plant in order to diminish the proportional cost of the constant part of running expenses, $i$. e., otherwise stated, there being given a certain necessary expenditure, invariable within certain limits with variation of size of boiler or of quantity of steam made, the larger the amount of work done without increasing this constant expense, the cheaper will the steam be made.

The larger the plant supervised by the engineer the less the total cost per pound of steam made, other conditions of economy being unchanged.

NOTE ON THE ECONOMY OF THE WINDMILL AS A PRIME MOVER.

\section{By Alfred R. WolfF, M.E.}

[A paper read before the American Society of Mechanical Engineers, April 21, 1882.]

In the course of professional work I have repeatedly had occasion to investigate the question of the impulse of wind upon windmills, and to observe the economical performance of the latter. From time to time I have published various results of these investigations, but have not given a record of the actual economy of the windmill, the subject-proper of this note. Before, however, setting forth the special economy in the use of the windmill as a prime-mover for small powers, it is well to refer briefly to some publications which may be of interest in connection with the general subject.

For the early history of windmills and a description of European windmills, Fairbairn's "Mills and Millwork" may be consulted to advantage. For a description of the details of American windmills see article on Windmills in Appleton's Cyclopedia of Mechanics, 1880. For an account of experiments on windmills see Smeaton's " Miscel- 